\title{
AC 2010-1277: WHAT IS GLOBAL ENGINEERING EDUCATION FOR?: THE MAKING OF INTERNATIONAL EDUCATORS
}

\section{Gary Downey, Virginia Tech}

Gary Downey is Alumni Distinguished Professor of Science and Technology Studies and Affiliated Professor of Engineering Education, Women and Gender Studies, and Sociology at Virginia Tech. He teaches the undergraduate course Engineering Cultures, an approach to international education for engineers at home. It is designed to help engineering students learn to work more effectively with people who define problems differently than they do, including non-engineers, by critically examining their own identities and predispositions. Current Chair of the ASEE Liberal Education Division, he is also co-founder of the International Network for Engineering Studies (www.inesweb.org) and co-editor of its journal Engineering Studies (www.tandf.co.uk/journals/engineeringstudies). 


\section{What is Global Engineering Education For?: The Making of International Educators ${ }^{1}$}

One approach to the question "What is global engineering education for?" is to examine the career trajectories of international engineering educators to identify what led them to such work and made it worthwhile, sometimes at considerable risk to their careers. Drawing evidence from lengthy personal geographies written by sixteen international educators, this paper reports that a key feature of their pathways has been experiences outside home countries that led them to question their own knowledge and normative commitments and want others, prospective engineers in particular, to have opportunities for similar experiences. Characterized here as "adding identities" outside home countries, these transformational steps helped motivate subsequent efforts to add practices to engineering education that would challenge students to confront their assumptions about the knowledge contents and normative commitments of engineering identities and work. The sixteen educators include nine engineers adding new practices to engineering education as well as five non-engineers and two hybrid engineers/nonengineers contributing practices from external positions. The normative commitments in these practices sometimes include but always extend beyond education for global competitiveness.

\section{Education for global competitiveness}

The past two decades have witnessed rapidly expanding interest in the United States in preparing engineers for work outside the country [1-22]. The image of such preparation that has scaled up to dominance across engineering communities is "education for global competitiveness" [23]. The image of competitiveness emerged during the 1980s to refer to the economic relationship among countries. In this image, preparing engineers for international work is a crucial practice in a multi-sectoral (industry-university-government) effort to advance American economic competitiveness in a world in which private industry has gone multinational in scope. The broad image of economic competitiveness has arguably provided the dominant U.S. frame for planetary relations since the decline and end of the Cold War [24-31]. The expectation of a link between engineering education and economic competitiveness is not surprising since engineering educators have been adjusting curricula to fit the broader, evolving goal of low-cost production for mass consumption since the 1870s [32].

Since 2000, the image of education for competitiveness has also come to refer (both inside and outside the United States) to the career challenges of individual engineers participating in the globalization of industry. If industry has gone multinational, then individual engineers must gain "global competence" in order to successfully locate employment and build careers [33].

By 2004, the National Science Foundation (NSF) had officially embraced the image of economic competitiveness as grounding organizational mandates. A letter from the NSF leadership to the President's Council of Advisors on Science and Technology, for example,

\footnotetext{
${ }^{1}$ The research reported here was supported by NSF Grant \#DUE-0752915. Thanks to co-organizers Kacey Beddoes, Brent Jesiek, and Juan Lucena for collegial collaborations and committed friendship. Thanks to Workshop participants for openly sharing personal experiences, participating in candid exchanges, and granting permission to report from personal geographies what is still draft material. Finally, thanks to Joseph Herkert for managing the review of this manuscript as well as to three anonymous reviewers for enormously helpful comments and suggestions.
} 
characterized the goal of economic competitiveness as economic "supremacy" in a newly leveling world. "Civilization is on the brink of a new industrial order," the letter asserted. "The big winners in the increasingly fierce global scramble for supremacy," it continued, "will not be those who simply make commodities faster and cheaper than the competition." Rather, "[t]hey will be those who develop talent, techniques, and tools so advanced that there is no competition" [34].

The image linking global engineering education to economic competitiveness gained particular force in official engineering circles following the 2005 publication of Thomas Friedman's The World is Flat: A Brief History of the Twenty-First Century [35]. In 2007 the National Academy of Engineering, National Academy of Sciences, and Institute of Medicine together invoked Friedman to introduce their Rising Above the Gathering Storm: Energizing and Employing America for a Brighter Economic Future. "[T] he international economic playing field is now 'more level' than it has ever been," their report echoed, and the United States is decidedly not "investing in our future and preparing our children the way we need to for the race ahead" [36].

The National Academy of Engineering had already in 2005 named the stakes in competitiveness for individual engineering careers. "[E]ngineering will only contribute to success," it asserted, "if it is able to adapt to new trends and provide education to the next generation of students so as to arm them with the tools needed for the world as it will be, not as it is today." Engineers will have to be able to communicate not only with technologies but also with customers, it continued, for mass production is giving way to "a buyer-centric business strategy that combines mass customization with customized marketing." And since engineers will be working increasingly in international, interdisciplinary teams, they must achieve "an understanding of the complexities associated with a global market and social context” [37].

Rapid recent acceptance of the image of education for global competitiveness has granted unprecedented visibility to international engineering educators, many of whom have long labored in relative obscurity. What has motivated the work of international educators? What have been their objectives? To what extent do the normative commitments of international engineering educators fit or overlap with the emergent image of economic competitiveness?

\section{Personal geographies to map differences}

I and three co-organizers (Kacey Beddoes [Virginia Tech], Brent Jesiek [Purdue University], Juan Lucena [Colorado School of Mines]) invited sixteen international engineering educators to participate in a multi-step process to produce personal geographies of their careers. Since a goal of this project is to examine how practitioners understand their commitments to international engineering education, we worked with a flexible image of international education as learning activities that direct students' attention beyond the boundaries of the home country.

\section{Mapping trajectories into international engineering education}

A personal geography is a narrative map of a trajectory. The term originated among geographers but never evolved into a routine practice in that field. To those geographers who have produced personal geographies, it typically involves reporting personal experiences of trajectories through physical spaces (e.g., the home), especially to highlight experiences hidden by dominant images of those spaces [38-41]. This project asked participants to use the idea of trajectory metaphorically. While including movements through physical space (e.g., travels to 
India, Bolivia, California, Atlanta), it also refers to movements through institutional locations (e.g., faculty member in engineering or foreign languages, education administrator, department head, dean) and other relationships (e.g., collegial relations, relations with host individuals and organizations).

Producing personal geographies challenged participants to map their changing identities as they have traveled through work and life, focusing attention on key transitions in which they found themselves in new relationships with unfamiliar people and things, organizations and institutions. I describe these transitions as "adding identities." For the purposes of this project, the term "identities" refers simply to relationships among entities (id-entity). To help identify what made a particular step significant, contributors were asked to present themselves as engaged in changing relationships with others who were positioned differently. They accepted a challenge to pursue three sets of research questions about themselves and others at key moments: (1) How was I (were they) located? (2) What did I (they) know? (3) What did I (they) want? Think location, knowledge, and desire as a mnemonic device.

The sociologist of knowledge John Law has persuasively argued that research practices in the social sciences tend to overlook "[p]ains and pleasures, hopes and horrors, intuitions and apprehensions, losses and redemptions, mundanities and visions, angels and demons, things that slip and slide, or appear and disappear, change shape or don't have much form at all, unpredictabilities" [42]. At the same time, in generating the messiness that is everyday life through contingent actions of various sorts, one also always takes some things for granted, producing continuities in the process. The production of continuity is every bit as much a part of agency as the production of novelty or change. John Law describes studying the messiness of social life, after all, in a book with an introduction and conclusion, an ordered set of chapters, acknowledgements, glossary, notes, references, and index.

The personal geography contrasts with survey results, summaries of structured interviews, and content analysis of texts (to select a few common research practices) by disclosing or at least gesturing toward some of the messier phenomena of everyday life. Participants often speak of surprises and other contingencies. They too, however, leave much out. They are directed accounts, with directorial authority resting ultimately in the hands of the author (but note the collaborative process below). Readers can infer that much is left out of every decision, action, or event that an author reports. The relevant analytical concern is the extent to which including interactions and relationships that are not developed in an account would likely transform it in significant ways. As historian of technology Rosalind Williams put it in characterizing personal geographies, "One leaves out a lot in such exercises, so there is more coherence in the telling than in the living." But, s/he added, "still you can't create a thread if there isn't one."2

In the context of the dominant image of education for global competitiveness, the key issue in organizing research strategies for this project lay not in the extent they would make visible contingencies and complexities or call attention to continuities, although both are important and the differences among them are significant. The key issue also lay not in a goal of providing or approaching some sort of complete account of what is now taking place in international and global engineering education. Rather, it lay in what specific strategies promised to make visible or risked hiding in the identities of international and global engineering educators, especially the

${ }^{22}$ Email message, July 29, 2009. 
knowledge and normative contents of those identities. What in particular might be hidden by the widespread discussion of education for global competitiveness and its attendant legitimacy?

\section{Between program history and autobiography}

To prospective participants, the narrative form of the personal geography fell ambiguously between "program history" and "autobiography." The program history was most familiar to them. Its temporal form details the visions, practices, and outcomes of a specific educational initiative, a "program," apart from the agents involved in it. Common at meetings of engineering educators, the program history transforms the activities it reports into a kind of organism that experiences birth, development, and travel through time. The author may appear in the recounting of struggles, but the main protagonist is the program itself, and the narrative becomes its biography. The genre is relatively comfortable for program developers to produce because it ultimately doubles as description and promotion. I have not myself witnessed an educator offering a history of a stillborn, diseased, or otherwise pathological program.

At the other pole, the temporal form of the autobiography narrates many dimensions of an author's life simultaneously. With the author as protagonist, it makes any thought or action fair game for inclusion. Its organizing image is the "life," of which work is but a part. Authors of autobiographies typically present the life as a narrowly-construed mix of willful agency and unanticipated contingency, including what the author says or does or thinks on the one hand and what just happens to the author on the other. Although regularly gesturing toward the messiness of everyday living, it too ultimately finds continuities in some sort of organizing thread, often named in the title or subtitle.

Over the past two decades, anthropologists and other qualitative researchers in the social sciences have experimented broadly with analyses in narrative form that locate the researcher's point of view within the analysis [43-47]. Including the author in the text always risks reducing analysis to autobiography, introducing mere "narcissism," as social anthropologist Judith Okely put it in an early reflection on the issue. The reason for this is of course the danger of shifting the focus in the account from the object of study to the author. Yet perhaps most scholars today would agree with Okely's contention that "[s]elf-adoration is quite different from self-awareness and critical scrutiny of the self" and that including the author as a "positioned subject" in the text can add much to it [48].

Exactly what including the author in the analysis adds or subtracts depends upon the purpose of the project and the specific research and writing strategies one selects. Adams and colleagues, for example, examine "storytelling in engineering education" with the explicit goal of better understanding the emergence of an "engineering education research community." Their focus is, in other words, accounting for an observed convergence and possibly contributing further to it. They invited eight scholars, including three co-authors, to prepare "story poster" presentations at the national Frontiers in Education conference (supported by the IEEE). The organizers asked presenters to respond to a structured set of questions designed to evoke "insider knowledge" pertaining to "driving passions and goals, processes such as getting started and moving forward, difficulties experienced and ways to overcome them, and what they were learning about research." The session used these posters as an anchor for subsequent interactions among the 5060 participants, who posted sticky-note replies onto the posters and engaged in small-group

discussions. Session evaluations suggested that the experience helped build a stronger sense of community among participants, and the authors concluded that storytelling "makes explicit our 
implicit knowledge, promotes reflective practice, and provides entry points into a community of practice" [49].

This study contrasts with the storytelling project by explicitly asking participants to trace the trajectories of distinct careers. Like the authors of the story posters, participants responded to questions posed by the organizers. The questions differed not only in inviting reflection over long periods of time (authors could use up to 10,000 words), but also in introducing the image of a trajectory as a "sequence of encounters among different perspectives."

As in an autobiography, the temporality of a career matters greatly. What came before what, and when did the author acquire which identities? A life is of interest ultimately because of how its various parts stand in relation to one another, perhaps constituting a definitive whole. A career is of interest significantly because it is also a story of others. At every point it has position in relation to others whom one can see by means of those locations. The words "trajectory" and "geography" emphasize the changing temporal and spatial dimensions of relational location. A personal geography is as much about all those whom the subject has engaged as about the subject her/himself. All become protagonists, even if introduced only briefly.

\section{From author-meets-critics to collaborative co-authorship}

Project participants produced personal geographies in a process that lasted fifteen months. An initial telephone invitation was followed by a written confirmation asking participants to "both recount the emergence of your own perspective on global education for engineers and locate that perspective in relation to those around you." The first step in the writing process was a 500-word abstract to which, after collecting responses from co-organizers, I drafted a detailed 500-1,000 word response. The draft manuscripts were due two months prior to a workshop gathering. Each author wrote reviews of eight to nine other manuscripts prior to the workshop, and the organizers submitted separate commentaries.

The key feature of the workshop was that authors could not participate in the discussions of their manuscripts. The purpose was to transform the typical author-meets-critics exchange into a process of collaborative co-authorship. Discussions took place in two groups. Each thirty-minute session was led by a primary respondent who summarized the manuscript and written comments, followed by a second respondent who addressed points not raised by the first. All group members were responsible for contributing comments and suggestions for further developing manuscripts. Authors were limited to giving a one-minute introduction at the beginning and a two-minute response at the end.

Authors had three months to produce an initial revision, to which one co-organizer (Kacey Beddoes) and I responded with detailed comments and suggestions. The collection of second revisions is under review as a book manuscript.

One key potential limitation in any project mapping differences is incompleteness. Maps make some things visible while hiding others. The knowledge value of a map lies not in its validity or reliability but its plausibility [30]. The collection of personal geographies can be described as plausibly mapping the territory to the extent they identify and present key perspectives involved in international and global engineering education without omitting perspectives whose inclusion would force a redrawing of the terrain. Toward the end of the Workshop, one participant announced "Everyone's here!" to general assent. They meant that a range of identities occupied by international engineering educators was present. Yet it is 
important to acknowledge that only some positions with stakes in international and global engineering education show up in this volume.

With help from co-organizers, I took care to include the positions of engineering faculty and non-engineering faculty; tenured, untenured, and non-tenurable; U.S.-born and non-U.S.-born; male and female; white and of color; late, mid, and early-career; senior administration, mid-level administration, and staff; funded and funder. A paramount concern was including demonstrated leaders in international engineering education working on different types of educational practices. How they view or respond to the image of economic competitiveness is often difficult to detect in their publications and formal presentations. Nonetheless, I took care to include participants likely to be strongly committed to economic competitiveness, participants likely to be critical, and participants likely to be ambivalent, mixed, or agnostic. The resulting group includes nine engineers, five non-engineers, and two hybrids (initial degrees in engineering, advanced degrees in social sciences).

Not included are students, whether participating or non-participating; non-participating skeptics about international and global engineering education; donors, both individual and corporate; mediating individuals and organizations between the United States and other countries; or any of the multitude of positions and perspectives outside the United States that participate in U.S. practices of international and global engineering education, from employers of interns to university hosts of study-abroad students to what a number of contributors call "local partners." All these deserve serious study. The focus here is educators.

Another key potential limitation in a project mapping differences is that it does no more than assert the presence of complexity. The claim that one is demonstrating complexity by mapping differences can limit itself by feigning innocence. It can present itself as detached from the very interpretations of the issues it analyzes and hence lacking any responsibilities in relation to them. But analysis is never innocent because it always bears some relation to dominant practices in the arena under investigation [50]. Certainly one possible relation is no relation: an outcome can be irrelevant. This project explicitly seeks to enhance the relevance of its outcomes for readers interested in international and global engineering education as well as in engineering formation more generally through its techniques for construing careers as trajectories and collaboratively focusing attention on discrepant moments of transition and transformation.

The resulting conversation in the personal geographies also conveys a significant finding relative to dominant practices of engineering education: much of the work that has gone into international and global engineering education has not been about adding global competency to engineers as an instrumental skill. Certainly every contributor is struggling to assess how the development of his or her knowledge and commitments relates to the emergent image of education for global competitiveness. Some call attention to additional goals to complement education for competitiveness. Some emphasize alternative goals. Many resist the dominance of competitiveness as a primary, unquestioned justification for international and global engineering education. The significant news in this project is that all these trajectories are responding to and challenging dominant practices of engineering education more generally. The key issue is not, in the first instance, about economic competitiveness.

A recurring outcome of discrepant experiences adding identities outside countries was dissatisfaction with dominant practices of engineering education and a resulting desire and commitment to expand what counts as engineering and the identities of engineers. The strongest 
way to present this finding is to share and thoroughly analyze the full texts of the sixteen personal geographies. My approach in this more modest paper is to offer two key quotes from each personal geography and then briefly summarize their significance in relation to the balance of the personal geography. One quote describes a discrepant moment that led the participant to question and challenge previously-established identities and practices. The other offers insight into the normative commitment(s) in her or his pedagogical work.

\section{Adding practices that challenge existing boundaries: nine engineers}

\section{Adding attention to political, social, and human dimensions-Richard Vaz}

"Will we get to go to Venice to test it?" I asked jokingly. "Yes," he replied, "there's funding from UNESCO for us and you to go there next summer for installation and testing." Sure enough, nine months later I found myself checking into Boston's Logan Airport with a large, metal enclosure full of circuit boards, tubes, sensors, and other suspicious artifacts, headed to Venice for three weeks.

Confronted with the complexities and contradictions of international development, the students' cultural experiences caused them to rethink many of the assumptions they held about technological advance, social justice, and a sustainable future. Their work caused them to consider the views of multiple stakeholders and to wrestle with competing economic, environmental, and social issues; as a result, their simplistic assumptions about how the world works were often replaced with more nuanced and complex perspectives.

Rick Vaz (Worcester Polytechnic Institute) details steps he followed that led ultimately to work pushing students out of what he calls their "comfort zones." Beginning with an account of how serving as a project advisor in Venice pushed him far beyond his own comfort zone, he chronicles a trajectory leading him from professor of electrical engineering to dean of interdisciplinary studies. After finding that the "technical or scientific issues" of student projects were "relatively straightforward compared to the challenges posed by political, social, and human factors," he emphasizes the importance of including the latter in the education of engineers.

\section{Building an expansive life through research and education-Dan Hirleman}

I lived in student housing among the Danes, interacted (in broken Danish) with the great people in the machine shop, and took time off from working long enough to participate in the essentially-mandatory coffee breaks with all the faculty and staff of the Lab. . . This was my first real cross-cultural experience - I was the minority culture and was forced to look at American culture from the outside. One of my "kitchen-mates" was a follower of Trotsky, and I was able to hear (and argue for many late nights) about a different perspective on the success and/or failings of the U.S., capitalism, communism, and Christianity.

Global engineering education offers students a remarkable opportunity to lead more expansive lives, both personally and professionally. .. . A global engineer can go against an instinctive decision appropriate for their own culture with ease, by seeing the point-ofview of another culture that is more appropriate for the context, and make a counterintuitive decision accordingly. 
Dan Hirleman (Purdue University) says he started in global education with the goal of helping Purdue graduates reach a level of global competence that in turn should help U.S. industry sustain global competitiveness, i.e. with an "industry bias." But that focus subsequently broadened to include global service learning. He maintains that important service work is accomplished through industry, and that private companies are key vehicles for engineering work to contribute to the production and distribution of benefits. His personal geography describes how entering an international research community helped him realize the importance of having personal and work identities that challenge one another, keeping both stimulated and vibrant. A career commitment to service led to work on international standards, where he realized that participants tended to assume deployment in the developed or near-developed world, without much thought of the possibility that not all technology is appropriate for the developing world. Asserting that the goal of the engineering profession is to actually help people, Dan asserts that an expansive life insures expansive work by forcing a focus on broader impact.

\section{Expanding the practitioner to fit the person-Margaret Pinnell}

More importantly, when I was asked to manage programs developing war-related materials I also found my job to be in contradiction of my pacifist values and beliefs. How could I work on a program that seemed warlike to me?

[S]tudents have a broad range of good and bad experiences with service-learning. Equally important, community partners can also have a broad range of good and bad experiences with service-learning and can sometimes feel exploited for the benefit of the students.

Margie Pinnell (University of Dayton) calls attention to the attractions and tenure risks of diving into service learning for engineering students. In a pathway that includes co-op work, "taking time off to be a stay-at-home mom," and researching service learning to make sure it is sound pedagogy, Margie describes a desire to "provide the fuel a student needed to turn a spark into a flame-and to turn a dream into a reality." Her work in international service learning redefines engineering and knowledge-laden practice that exudes passion from its core, wholly engaging both personal and work identities.

\section{Adding a new engineering specialty-Joe Mook}

The importance of being in Hanover, for me, was much less about math than it was about myth - or more precisely, about shattering many of the myths I thought I knew about myself and the world I lived in. In shattering those myths I discovered that the truth was infinitely more interesting.

In the years since then, I've found that most students who try an international experience come home with essentially the same reaction. It is this real, life-changing, inner transformation, more than any other factor, which has motivated my efforts to contribute to international education in engineering. I want to enable and encourage as many other people as possible to have the opportunity to experience this, and given my profession as engineering educator, my efforts to do so have naturally been directed at engineering students. I believe that international experience significantly improves lives on both a professional and a personal level. That's my "why" for getting involved in international education; and I don't have a "why not."

Joe Mook (State University of New York at Buffalo) explains how his commitment to international engineering education developed after achieving tenure in mechanical and 
aerospace engineering, beginning with a research trip to Germany. Personal dimensions of his life that previously had no relevance to his work suddenly became central. Accepting a position as Assistant Dean of International Education led him to challenging work that in his judgment warranted being called a "primary academic specialty focus." International education should be integral to both engineering education and engineering research.

\section{Stepping out of technical boxes-Anu Ramaswami}

Perhaps because of the smaller number of Indians in Colorado or because I had grown away from the Indian (IIT-ian) graduate student subculture, I started developing a much clearer link with contemporary American culture (at least as practiced in suburban Front Range Colorado), than I had during my years in Pittsburgh. . . . Perhaps I was getting assimilated, and at the same time, I had the opportunity to delve deeply into Indian (Hindu) philosophy, being responsible as a volunteer teacher for transmitting this heritage to our first generation Indian-American children in the US. Through all these social interactions and obligations, I was learning more than ever, unconsciously crossing many cultural lines and gaining confidence in stepping out of whatever boxes I was perceived to be in.

I found I had a better understanding of the infrastructures in urban Denver and their social ramification than those in remote tribal areas of India and other parts of the developing world. I also found myself relieved to be back in the realm of applied research in sustainable development, as the dynamics of donors, benefactors, beneficiaries and their varying agendas in international service projects had caused me to lose much sleep over their ethical ramifications.

For Anu Ramaswami (University of Colorado Denver), coming to the United States was not the "dramatic culture shock" that leaving the country was for the American-born participants. The United States "in all its complexity" provided an opportunity to pursue broader questions in a more amorphously-defined field-environmental/sustainability engineering, than she had experienced in civil engineering in India. Later in her career, undertaking humanitarian work in India, awareness of her ignorance about who set local agendas in tribal communities, whose knowledge counted, etc. did not make her retreat to narrowly-defined practices of technical problem solving. Rather, Anu threw herself into practices of research and education that pushed herself, her students, and her colleagues to recognize the limitations of their knowledge and both tap and engage important knowledge in communities aspiring to environmental sustainability.

\section{Questioning what you design-Linda Phillips}

After climbing the industry ladder of success, I grew discontented clearing and paving green spaces with unneeded retail space or coaching and managing my employees to do the same. .. . [In a new teaching position], I found myself interjecting lessons from my last (and toughest) industry project: a retail center on a developing Caribbean island. There I'd learned that Haitians valued having a job each day more than the pay itself. Although they were paid per piece, for them it was more honorable to work slowly and make the job "last" than hurry the installation to get final pay. I also learned the importance of alternative designs for rainwater harvesting and sewage treatment and the importance of designing pipe sizes to be "nested," minimizing shipping costs to the island. And sadly, I learned some of the consequences of a litigious and greedy US society. The project/facility owner sued, taking advantage of the situation to earn a fast buck. 
Many students have not done much physical labor before ISD [International Senior Design], and jobsite tasks test them. They quickly appreciate and respect the construction workers' strength and stamina as well as their wisdom. Students quickly learn that ISD is not a vacation. The discomfort and disruption of their routine and the removal of US amenities add to the impact of the experience.

Linda Phillips (Michigan Tech/University of South Florida) describes a pathway that took her from a first career as a construction executive to a second as a university lecturer teaching international senior design. Uneasy about paving green spaces and longing for something "more meaningful," she embraced an opportunity to teach despite the ambiguities of her position on the faculty. Having come to believe that a "sustainable and constructible design is generated only when an engineer understands the situation in the field," she wants students to add field identities that challenge and shake up as dramatically as possible their expected identities as construction engineers. Only then might they fully appreciate that it really matters what construction engineers design and build.

\section{Building more than a national resource-Les Gerhardt}

That same travel ... provided less than pleasant images to be stored in my 'memory box' which I can't forget, and in a different but equally important way further fueled my developing passion for global engineering education. These include a child of not quite 10 years old, hawking fish on the street with a glazed look the result of not enough sleep the night before; a child whose formal education had already been completed. Another was of a family living in a lean-to of corrugated metal, the back of which was provided by the imported marble of the adjacent elegant high rise next to it. This was not TV. This was real. I felt grateful for when and where I was born. I have only known freedom, never known hunger, and always slept in a clean bed. But that was too often overshadowed by the realization of my remaining obligation to others less fortunate, especially the children of this world.

Moreover, these years at Bell further solidified in my mind the importance of gaining an international perspective for the field of engineering. . . . It was then I experienced a real awareness that the science and engineering workforce needed to be regarded as more than a national resource. I now emphatically feel that global issues can only be solved by using global intellectual resources, and that the interdependency of countries with respect to environment, energy, finance, health of our planet and ourselves mandate cooperation rather than conflict. On the fine line between cooperation and competition, let us choose to err on the side of cooperation with peaceful longterm objectives.

Lester Gerhardt (Rensselaer Polytechnic Institute) traces a career pathway that began with space flight simulation at Bell Aerospace, led to "try[ing] out academe" in a faculty position at Rensselaer, and a flurry of activities in international engineering education. These include cofounding and continued leadership of the Global Engineering Education Exchange Program, leadership in structuring and implementing the Rensselaer Education Across Cultural Horizons Program (REACH), the goal of which is to ultimately require an international experience for each undergraduate, and serving as senior adviser to the President of the Institute for International Education (IIE). Highlighting the crucial knowledge he gained through international travel, Les explains how these personal experiences supported a revised image of the larger service responsibilities of engineering. Les continues to work to insure that awareness 
of the possibilities of cooperation and the responsibilities of privilege emerge from required rather than optional curricular experiences in engineering. For him, globalizing engineering is about remapping the identities of engineers from the country to the planet.

\section{Adding the humanitarian to the competitive-Alan Parkinson}

After two months studying the language, I continued my journey west from Hawaii with a group of 40 other missionaries to the Japan Central mission, with headquarters in Kobe, Japan. As I struggled during the first six months to adapt to everything which was new and different, such as the language, food, culture, housing, transportation, etc., I felt almost as if I had been transported to a another planet. . . Missionaries are taught to embrace the culture and people among whom they work. Many are profoundly affected by their missions, and many develop a deep love for the country in which they served. I returned home with great respect for the culture and accomplishments of the Japanese people.

I have been a little bit surprised regarding how I have come to feel about humanitarian projects. Previously I viewed study abroad as a way to learn what developed countries were doing and how to prepare our students to remain competitive in the global marketplace. However, I have come to understand that another motivation for promoting international technical experience relates to the range and scale of technological needs of humankind in the $21^{\text {st }}$ century. . . . Students also develop an understanding of themselves as member of the world community and are often humbled by what they enjoy as citizens of the United States.

Alan Parkinson (Brigham Young University) explains that applying for the deanship led to many sleepless nights, in part because he offered a vision of internationalizing engineering education at the school that he knew would be difficult to implement. Holder of a recentlyawarded master's in business administration, the full professor in engineering and new dean focused on making BYU more competitive among engineering schools and the United States more competitive economically in the world. Yet working with passionate, committed faculty who wanted to "make a difference" in other ways through international education made him refocus on the University's motto, "Enter to learn, go forth to serve." Without giving up on economic competitiveness as a goal for both the country and the individual student, Alan explains that he "realized students need to place their engineering solutions within their human context and understand the impact engineering can make on developing countries.",3

\section{Expanding performance measures (for sustainability engineering)_James Mihelcic}

I tend to pursue things that integrated my heart and personal convictions with the structure of my engineering brain. I was always willing to devote the same time to an undergraduate in need as to a doctoral student of great promise. And I was always willing to assist a small community group that needed some technical advice as much as a larger better funded entity that contacted me. So I quickly set up a meeting with the Peace Corps representatives who immediately expressed excitement in creating what would become the first Peace Corps Master's International program in engineering. . . . In all honesty, the timing of student interest was related I think to an awakening that was occurring amongst the Millennium generation, who were now expressing stronger interest desire for programs related to

\footnotetext{
${ }^{3}$ Email communication, March 16, 2010.
} 
environmental degradation, climate change, poverty, justice, renewable energy, and serving others.

From personal experience, it may seem daunting to learn a new body of literature and move a research publication through peer review when perhaps the reviewers are skeptical of the quality of research coming from a village in Africa. Promotion committees and department chairs may also not fully understand a new body of literature that is more interdisciplinary and perhaps has a more applied audience of nongovernmental organizations. Fortunately, motivated students, if pointed in the right direction or provided a few atypical key words, will seek out new information and journals.

James Mihelcic (University of South Florida) explains a shift in his research and teaching from environmental remediation to "proactive approaches to the prevention of pollution," especially by developing an international master's program in cooperation with the U.S. Peace Corps. He did not anticipate just how much attempting to "merge conviction and values with my profession" would put him at odds with established practices of research and teaching in civil engineering. Ultimately, he found himself seeking a scholarly environment whose explicitlydefined strategic mission fit more closely the larger objectives of his work.

\section{Contributing practices from outside positions: five non-engineers and two hybrids}

\section{Educating for present realities-Bernd Widdig}

Crossroads in life often emerge through fortuitous encounters. In my case it was my decision as a young student at the University of Bonn who minored in German literature to take a seminar with a visiting professor from Stanford University. The way he taught his class, his interaction with us as students brought a sudden ray of sun into our otherwise mostly grey and uninspiring German academic landscape. He must have sensed my light deprivation, because he encouraged me to come as an exchange student to Stanford, and after I finished my German Staatsexamen in Economics, Political Science, and German Literature I followed his call.

It is safe to say that Foreign Languages was operating at the periphery of MIT's academic culture. My senior colleagues bemoaned this fact and expressed their discontent in differing shades of anger, cynicism, and a peculiar sort of cultural elitism to which some colleagues in the humanities resort in the presence of engineering and science colleagues with large research budgets and hordes of graduate students. . . I soon asked myself how I could connect my work and interests with the large engineering and science community. Contrary to my colleagues, I saw our peripheral status as an advantage.

For Bernd Widdig (MIT/Boston College), coming to the United States was about having the opportunity to do German Studies, enabling him to go beyond examining the established literary and cultural canon of the country (Germanistik) to examining its "present cultural reality." These broader interests motivated risky work developing the MIT-Germany internship program. To become an educated person, Bernd insists, one has to be able to understand and reflect intelligently on the "messiness of real life" in the present. Shifting entirely to international education proved to be deeply satisfying, giving him the repeated sense he is making a significant difference in students' lives. 


\section{Saving students from choosing between content and language-Michael Nugent}

When I graduated high school, I had almost a full year of university study under my belt and I decided to take the winter quarter to travel to Europe to visit two exchange students. ... During the stay at my friend's house in Stockholm, I realized that English conversation on my behalf quickly reverted back to Swedish among friends and family, leaving me feeling as if I had suddenly been isolated in bubble wrap. . . . Being forced to use [German] to communicate in my home stay environment in Southern Germany made all the difference in my German skills. It was in this environment where I began to see the multiple levels of complexities involved in mastering a language. Successfully completing homework and classroom exercises was one thing, negotiating on a variety of levels in a home environment was something entirely altogether different. I decided on this trip that one of my major educational goals in life was to be able to engage effectively in discussions on contemporary issues in a second language.

Unlike most study abroad, these initiatives internationalized degree programs, such as Petroleum Engineering, Aerospace Engineering, or even Nursing, by integrating the academic or professional degree programs at institutions here in the United States with those in other countries. In order to achieve this ambitious outcome, faculty at institutions in one country would need to work closely with their colleagues at partner institutions abroad to create curricula and pathways for students to benefit from their time overseas. As this program developed, we began to refer to this experience as "meaningful time abroad" in the FIPSE office.

Mike Nugent (The Language Flagship, National Security Education Program) describes how early interest in language learning (German, Swedish, French, Spanish) deflected him away from a career in music and into language instruction, higher education policy, and ultimately the administration of government funding programs for language learning. At the U.S. Department of Education, he confronted the many barriers among participants in international consortia that prevent student experiences from scaling up in systematic and smooth ways. And realizing the importance of linking language education to education in content areas such as engineering ultimately led him to help found a program focused on exactly that.

\section{Connecting literature with engineering work-Phillip McKnight}

[A]s an MA student at the University of Colorado in the late 1960s, when foreign languages were flourishing (thanks to Sputnik!), I had organized a symposium addressing the question, "why do we study Germanics," framing it with Goethe's famous $18^{\text {th }}$ century play Faust, in which the protagonist rejects his isolated and frustrating life in a university research lab to answer the call to "flee out into the wide world" (Flieh! auf! hinaus ins weite Land!). If the principle work of the principle "employer" of German professors (at the time probably $30 \%$ of research in the field focused on this author and period) admonished us to get rid of this pile of books and test tubes to find out "what the real essence that held the world together" was (Dass ich erkenne, was die Welt/ Im Innersten zusammenhält), why were we not taking his advice? Why was there no connection between what we read and learned and life itself?

I have not lost sight of my passion for literature that really is connected to life, and so therefore the question becomes, how can intelligence function to influence policy? Do we want to produce engineers - or other graduates for that matter-who will work quietly on their projects and in their labs producing commercially viable products without regard to 
their impact on the environment or economic structures, or do we want to produce an intelligentsia that will understand how to employ technology, science and the humanities in ways that have a principled, positive impact on society and the world in which we live?

As a single parent working in a motorcycle shop, Phil McKnight (Georgia Tech) participated in a program designed to provide Ph.D.'s in the humanities with the tools to switch careers when an opportunity to teach German led to a university faculty career seeking to connect literature to life. Describing himself as an "incurable dreamer," Phil has embraced worlds of business not because of a principled commitment to advance business and technology themselves but to become a critical participant finding ways for "experts in culture, language, and society" to exert their influence in a credible manner. Language learning and study abroad for engineers and everyone else, Phil maintains, "offer perhaps the best chance for creating the kinds of graduates who will provide leadership in solving the major problems confronting society." He wants to help produce in engineers and other technical experts "high ethical standards and a great appreciation for developing mutually beneficial business deals that would not leave the global impression that the U.S. was ruthlessly exploiting other countries for profit . . ," but that "would demonstrate our collaborative spirit for improving our planet and our diverse societies."

\section{Sharing the challenge of basic values and political assumptions-John Grandin}

As the twenty-year-old son of the Baptist minister from a small, homogeneous New England community in central Massachusetts, being sent to Germany in the summer of 1960 ushered me into a very different world. . . . My host "parents" had lived through both world wars and had been driven out of their homeland in Eastern Europe and forced to start a new life in the West. . . Living in their home for three months, sitting with them at their dinner table every day, watching how they interacted as a family, hearing their concerns and aspirations, finding myself and my worldview challenged by them on a daily basis, the world took on new dimensions for me in that short summer, as it did for them as well. I found many of my own basic values and political assumptions challenged and began to understand, for example, that being an American was taken quite casually by my friends and myself and that most of us were totally unaware of the life experiences and priorities of people in other parts of the world, or of their expectations and hopes of us.

I landed a two-year lecturer position at Union College in Schenectady, New York and thus had the luxury of teaching some bright young kids and learning that I could impart to them not only knowledge of the language, but the importance of understanding the perspectives of people from nations other than our own. This was a powerful and formative time for me, which gave me the confidence to teach and believe I could make a difference through my role as a potential professor of German.

John Grandin (University of Rhode Island) presents a pathway showing how an early commitment to teaching German devolved into frustration and flirtation with a career shift to building construction before hitting on the idea of building a five-year double major in engineering and a foreign language. Finding fulfillment in applied language learning, John became what other participants called the "father" of international engineering education by energetically encouraging and assisting others through the annual Colloquium on International Engineering Education. Accepting that integrating language education and engineering education often includes attention to "internationalization, global awareness, and the need to keep the 
nation informed and competitive," John insists that the real benefit of international engineering education is to help students gain experiences "such as I myself had known."

\section{Engaging foreignness-Gayle Elliott}

I still remember getting off the plane where everything was different. It was communist, and we were not permitted to go anywhere alone. We were taken by bus to two different cities (Moscow and, at that time, Leningrad). We were cautioned about so many things, including being warned not to talk to the Russians or give them anything "American." One time, ignoring the warning, I gave some kids a pack of gum, and in return they gave me a small red plastic star with a tiny photo of (I believe) Yuri Guggari as a baby in the center. I returned to the US with my eyes opened. Now, 35 years later, I have spent about three years of my life outside the US, including a six-month period living in Japan.

And finally, I loved working with the students. They came to me as immature freshmen, left to go abroad with excitement, and returned home as mature, changed adults, with tremendous self-confidence and the belief that they could succeed anywhere. The opportunity to help students reach that conclusion is extremely rewarding. And many of the students developed the same feelings for the program. They appreciated my efforts. They often remain involved, attending functions and speaking to other students groups. And when possible, a few have begun participating in the program as employers -- hiring co-op students in the US and sending them on assignments overseas.

Gayle Elliott (University of Cincinnati) explains how she came to her work as a faculty member in international professional education through a circuitous route that included administrative positions, an "obsessive" commitment to advancing her education, and a job opportunity that led her to realize she might be able to bring professional work together with personal interests. A first-generation college student, Gayle found that first experience abroad to whet a lifetime interest in engaging foreignness through frequent, extended travel. She found a passion in helping students "open their eyes" just as hers had been opened with the help of others.

\section{Making visible and transforming the politics in engineering-Juan Lucena}

Even after being born and raised in Colombia, I found out that I knew little about the history of my own home country. Reading and researching about Colombian engineers has challenged me to re-discover my Colombian self. . . . I have begun to understand how protestant values permeated my traditional Catholic family. Reading the history of $20^{\text {th }}$ century industrial development helped me understand my father's political trajectory, beginning with my grandfather's political career and their struggles during Colombia's most violent decade (1950s). I now understand their attitudes towards and struggles with my decision to study engineering in proper historical context. . . . At a time that legally I was becoming more American, existentially I was becoming more Brazilian, Colombian, and Mexican as I researched, wrote and taught about the histories of engineers in these countries.

I am committed to challenge engineers to critically reflect on whether engineering problem solving (EPS) and engineering design methods are appropriate approaches to humanitarian and community development problems. I want them to question whether expectations of service to their societies as engineers coupled with desires to help, often motivated by 
religious missionary views, is all they need to try to solve other people's humanitarian and development problems.

Juan Lucena (Colorado School of Mines) bucked family tradition on his father's side by eschewing law and medicine for education and an identity in aeronautical engineering. Yet he found himself unwilling to contribute to what he has seen as Cold War or post-Cold War militarism, as well as to the spread of free-market ideology across Latin America. Shifting his educational focus from engineering to interdisciplinary science and technology studies and struggling to transport the Engineering Cultures course from Virginia Tech to Embry-Riddle Aeronautical University and Colorado School of Mines, he now works through a variety of teaching and research projects to help engineers and engineering students recognize and critically analyze the politics of engineering.

\section{Integrating critical identity work-Gary Downey}

One night in eleventh grade, I had had a dream entirely in Spanish. I had been studying Spanish since the seventh grade and would be approaching working fluency when I finished high school. I experienced the dream as a wholly altered reality. I had joined a different world. People and things were different when I engaged them through the lens of Spanish. At the time, I was mostly proud I could have the dream at all. I was gaining mastery of the language. But it also triggered a developing interest in perspective and point of view. What most struck me is that the language itself seemed to have a point of view.

My curricular work began to step beyond Engineering Cultures and dive deeper into the heart of engineering curricula in 2004 when I was invited to deliver a keynote address to the World Congress of Chemical Engineering on engineering education. In preparing this address, it suddenly occurred to me that while the practices of collaborative problem definition emphasized in my course may be supplemental to practices of mathematical problem solving, they were not supplemental to everyday engineering work. Indeed, problem definition was both an essential part of engineering practice and upstream of problem solving. In the same way that I had decided to contest the meaning of global competency, I decided to contest the core of engineering curricula, arguing that the core practices should include collaborative problem definition alongside mathematical problem solving.

Gary Downey (Virginia Tech) presents a trajectory that locates his work in international engineering education alongside other teaching and research designed to integrate into engineering education practices of critical self-analysis. Feeling "confined by the requirements of my curriculum [in mechanical engineering]", he sought graduate training in anthropology to learn how to analyze conflicting perspectives in technological controversies. Moving into science and technology studies as a faculty member offered both the freedom to develop a variety of curricular interventions in engineering education and the constraints of peripheral location--all the courses have been electives. This work has led in turn to efforts building an academic field of "Engineering Studies" that would place special emphasis on examining the normative commitments of engineers and engineering and to research examining practices of "problem definition and solution" in engineering pedagogy and the engineering workplace. 


\section{What is global engineering education for?}

In adding identities outside countries, participants in this project encountered discrepant moments and experiences of incongruence that led them to see themselves and their knowledge differently. They learned to recognize that what they had always taken for granted in both professional and personal practices could have been different, and indeed frequently became different in the process. The big payoff in accepting and engaging incongruence was in learning to analyze their own locations, forms of knowledge, and desires in relation to those of others. The privilege of such learning introduced, in turn, the very possibility of scaling up other practices in engineering pedagogy in addition to, alongside, or in place of those that have been dominant. They became committed in particular to practices of international and global engineering education.

For the nine engineers, the key encounters with incongruence came after they had already built identities as engineers. For Rick Vaz and Joe Mook, following work activities abroad produced encounters with other social and political points of view and multiple nontechnical dimensions of engineering work that motivated dramatic changes in their career paths. Rick began insisting that quality engineering work necessarily includes attention to its social, political, and cultural dimensions, and Joe began insisting that international education can be an engineering specialty. For Margie Pinnell, Jim Mihelcic, Linda Phillips, and Les Gerhardt, the new identities they gained beyond the United States came not through international travel but by experiencing changes in their work activities that made them rethink and rebuild their identities as engineers in the world. Margie found herself a technical manager of work producing materials for making war. She redirected her travels to include supporting a program designed to help advance peace. Jim realized his focus on environmental remediation did not address the larger issue of the sustainability of life. He expanded the boundaries of environmental engineering to include it. Linda extrapolated years of construction work to an image of construction engineers paving green spaces everywhere. She redesigned education in senior design to expand what students consider professional practice, including both variable construction practices and new stakeholders. While working on the Apollo project, Les realized he had been trained to think of engineering as only a national resource. He began devoting himself to insuring students define engineering service in broader terms. Anu's case is unique because identities inside and outside her country of origin were part of her developing identity as an engineer in the first place. After struggles with humanitarian work in her home country, she refocused on expanding the boundaries of work in environmental engineering to include what communities want.

Dan Hirleman and Alan Parkinson might appear at first glance to be working wholly in terms of the image of competitiveness. Both are helping students compete for jobs with companies that have built multinational networks, and they link this work to the goal of advancing American competitiveness. Yet they too are altering the contents of engineering practices in their work. In Denmark, Dan encountered something entirely new, the experience of being an outsider. His search is for ways of understanding and doing engineering with other engineers and stakeholders who think differently, not against them. Alan established global competency as a strategic goal for his college in the interest of competitively attracting students, placing graduates, and empowering a country threatened by China. Actually supporting programs led him to expand his understanding of engineering service and engineering work to include humanitarian goals and activities. 
The non-engineers and hybrids all found working to expand the identities of engineers to solve identity problems of their own. Bernd Widdig, Phil McKnight, and John Grandin all resisted the practice of separating literature from everyday life in the discipline of Foreign Languages and Literature. Bernd accepted the risk of appearing to produce an "in-house Berlitz school" in order to connect his work with the realities of the present and build an internship program to send MIT students to Germany. Phil worked to build language programs for professionals at two institutions with the goal of producing knowledge workers who "will understand how to employ technology, science, and the humanities in ways that have a principled, positive impact on society and the world in which we live." John built a local initiative and then facilitated a national movement in international and global engineering education to insure that students gain "not only knowledge of the language" but understanding of "the perspectives of people from nations other than our own." Mike Nugent saw himself reproducing the separation between language learning and content learning that had so plagued him in earlier years, despite watching European professionals evidently achieve full integration of the two. For him engineering education provided both an opportunity and a test site for funding programs that would achieve in the United States what he had seen in Europe. Gayle Elliott took the separation of work life and home life for granted as she worked her way up in administrative positions within a university organization. Realizing she could help students while making use of the knowledge she had gained through international travel solved a problem she didn't know she had. She had come upon a way to connect together her personal and her work identities, producing a vocation in the process.

Finally, Juan Lucena and Gary Downey concentrated on using their non-engineer identities to inform the engineering identities of both themselves and others. Juan has worked to add practices to engineering by making visible the power relations and politics in engineering and by helping "committed people trying to construct alternatives to engineering for military and free-market development. Gary has built a program of teaching and research to integrate into the heart of engineering formation the practices of mapping the locations, forms of knowledge, and desires of stakeholders in engineering work.

For participants in this project, it was encountering conflicts between work identities and personal identities in experiences outside home countries that frequently had the jarring effect of introducing new dimensions of choice. What they had previously taken for granted as their knowledge about themselves and their world became the product of their own experiences and judgments, their own decisions. An established identity and associated forms of knowledge became a point of view. And as at least some of what was given became variable, subject to chance and change, futures became more obviously dependent on normative questions and decisions in the present. What are my responsibilities? What do I want for myself? What do I want to do for others?

One set of concerns discussed in the workshop about practices of international and global engineering education workshop points out that little attention has been given to their effects on partners in other countries. "Almost all the articles [on international and global engineering education] I have reviewed to date," points out Anu Ramaswami (University of Colorado, Denver) in her contribution, "have addressed scale of the input in terms of numbers of interns or student participation. What about the scale of the output? What impacts are these programs having on the world outside of academia?" It is indeed essential to study and debate the effects international and global engineering education have not only on participants, future employers, 
and the abilities of home institutions to recruit good students but also on those hidden or made less visible by the dominant image or images to which one subscribes. It means inquiring into the local economy of home-stays for study-abroad students. It means asking what exchanges mean for host educational institutions or internships for host companies. It also means inquiring into the actual machinations of humanitarian, development, and sustainability projects, taking care to map flows of benefits and costs both inward and outward. It matters greatly where a program and its student participants end up. A significant body of research now exists, for example, critically examining the participation of engineers in international development [20, 51-56].

It also matters, at the same time, where students start and in what directions they head. Practices of education are in part about movement. They are about learners and those who lead them starting off somewhere and then heading off in particular directions. They are about acquiring identities, gaining knowledge and normative commitments along the way. For this reason, to understand and assess practices of international and global engineering education, it is crucial to include attention to where students start and the contents and directions of the steps they take. It is also crucial to make visible the types of questions they may be less likely to ask about themselves and their work, especially the effects of their work on others, if their education does not include adding identities outside the country.

Coming to international and global engineering education from different directions, participants in this project have all effectively become engineering educators with distinctive normative commitments and practices. Their trajectories are important and instructive examples of what might be called "encounters with an American engineering self" [57]. All participants have had to find ways of responding to the emergent image of education for global competitiveness. For some participants, the commitment to competitiveness has been essential. For others it has been something to tolerate, work around, or actively resist. In no case was it exclusive. These findings suggest that to grant exclusive attention to economic competitiveness in building or advocating practices of global engineering education is both misleading and carries the danger of overlooking or actively undermining other important benefits from such experiences. Every participant, in particular, did find in practices of international education important opportunities to critically examine and extend beyond dominant practices of engineering teaching and learning. What might it take to embed such opportunities more systematically in the formation of engineers? Indeed, can such be accomplished without practices of international engineering education?

Toward the end of the workshop, John Grandin announced "it's fine with me" if engineering students "are warmed" to international and global engineering education because they think it will "open up new career opportunities" and "help with American competitiveness and so forth." Engineering students tend to be "pragmatic," he said, meaning they tend not to ask questions about the boundaries of their identities and work as engineers.

Then leaning back in his seat and folding his arms with an air of confident expectation, he described what typically happens when students come back. "They'll come into my office and say, 'Dr. Grandin, I learned things that I never had any idea I was going to be learning." They go on to explain in particular what they learned about themselves in relation to others they could now see and begin to understand. Invariably, he said, it is "a self eye-opening experience." Because "students can tell you at the end of the experience" what they can now see and how differently they understand themselves in the world, "I don't worry about it at the beginning." 


\section{References}

[1] Higgins, R.J., "Global Innovation for Engineers: Experiences in Preparing Engineers for the Global Enterprises of Their Careers," American Society for Engineering Education Conference \& Exposition, Seattle, Washington, 1998.

[2] Atkinson, D., B. Allert, E.D. Hirleman, and E. Groll, "International Short Courses and Domestic Orientation Sessions for Engineering Students," 9th Conference on International Engineering Education, 2006.

[3] Lohmann, J.R., "Strengthening the Global Competence and Research Experience of Undergraduate Students," Atlanta, Georgia: Georgia Tech Institute Communication \& Public Affairs, 2005.

[4] Andersen, A.," Preparing Engineering Students to Work in a Global Environment to Cooperate, to Communicate, and to Compete," European Journal of Engineering Education Vol. 29, No. 4, 2005, pp. 549-558.

[5] Blumenthal, P., and U. Grothus," Developing Global Competence in Engineering Students: U.S. and German Approaches," Online Journal for Global Engineering Education Vol. 3, No. 2, 2008, Article 1.

[6] Allert, B.I., D.L. Atkinson, E.A. Groll, and E.D. Hirleman," Making the Case for Global Engineering: Building Foreign Language Collaborations for Designing, Implementing, and Assessing Programs," Online Journal for Global Engineering Education Vol. 2, No. 2, 2007, Article 1.

[7] Grandin, J.M., and E. Dehmel," Cross-Cultural Issues in Educating Engineers for the Global Workplace," The Journal of Language for International Business Vol. 8, No. 2, 1997, pp. 1-15.

[8] Chaturvedi, S.E.A., "Glboal Engineering in an Interconnected World: An Upper Division General Education Cluster at Old Dominion University," American Society for Engineering Education Conference \& Exposition, 2001.

[9] Korta, L., "Educating International Engineers: A Midwestern US University Experience," American Society for Engineering Education Conference \& Exposition, 1999.

[10] Swearengen, J.C., S. Barnes, S. Coe, C. Reinhardt, and B. Subramaniam," Globalization and the Undergraduate Manufacturing Curriculum," Journal of Engineering Education Vol. 91, No. 2, 2002, pp. 255-261.

[11] Sheppard, K., P. Dominick, and Z. Aronson," Preparing Engineering Students for the New Business Paradigm of International Teamwork and Global Orientation," International Journal of Engineering Education Vol. 20, No. 3, 2004, pp. 475-483.

[12] Downey, G.L., J.C. Lucena, B.M. Moskal, T. Bigley, C. Hays, B.K. Jesiek, L. Kelly, J.L. Lehr, J. Miller, A. Nichols-Belo, S. Ruff, and R. Parkhurst," The Globally Competent Engineer: Working Effectively with People Who Define Problems Differently," Journal of Engineering Education Vol. 95, No. 2, 2006, pp. 101-122. 
[13] Grandin, J.M.," Preparing Engineers for the Global Workplace," Online Journal for Global Engineering Education Vol. 1, No. 1, 2006, Article 3.

[14] Elliot, G., C. Cates, B. Dansberry, and L. Trent, "Preparing Engineers for the Global Workplace: The University of Cincinnati, Paper 2006-1021," American Society for Engineering Education Conference \& Exposition, 2006.

[15] Parkinson, A.," Engineering Study Abroad Programs: Formats, Challenges, Best Practices," Online Journal for Global Engineering Education Vol. 2, No. 2, 2007, Article 2.

[16] Groll, E.A., "Introduction to and Experiences with the Undergraduate GEARE Program," 9th Annual Colloquium on International Engineering Education, Newport, Rhode Island, 2006.

[17] Mihelcic, J.R., L.D. Phillips, and D.W. Watkins," Integrating a Global Perspective into Engineering Education and Research: Engineering International Sustainable Development," Environmental Engineering Science Vol. 23, No. 3, 2006, pp. 426-438.

[18] Del Vitto, C.," Cross-Cultural 'Soft Skills' and the Global Engineer: Corporate Best Practices and Trainer Methodologies," Online Journal for Global Engineering Education Vol. 3, No. 1, 2008, Article 1.

[19] Gerhardt, L., and V. Renganathan, "Incorporating Global Perspective in U.S. Engineering Education," American Society for Engineering Education Conference \& Exposition, 2008.

[20] Riley, D., "Resisting Neoliberalism in Global Development Engineering," 2007 American Society for Engineering Education Conference \& Exposition, 2007.

[21] Parkinson, A.," Global Competence: Why Is It Needed? What Does It Mean? What Is Most Important?," Online Journal for Global Engineering Education Vol. 4, No. 1, 2009.

[22] Grandin, J.M., and E.D. Hirleman, "Educating Engineers as Global Citizens: A Call for Action / A Report of the National Summit Meeting on the Globalization of Engineering Education," Online Journal for Global Engineering Education, 2009, Article 1.

[23] Jesiek, B., and K. Beddoes, "Development, Competitiveness, and Globalization: Historical Perspectives on the International Dimensions of American Engineering Education," What Is Global Engineering Education For?: The Making of International Educators," 2010, manuscript.

[24] Goldman, S.L., (Ed.) Science, Technology, and Social Progress, Bethlehem, Pennsylvania: Lehigh University Press, 1989.

[25] The National Commission on Excellence in Education, A Nation at Risk: The Imperative for Educational Reform. A Report to the Nation and the Secretary of Education, U.S. Department of Education, Washington, D.C.: The National Commission on Excellence in Education, 1983.

[26] American Society for Engineering Education, "A National Action Agenda for Engineering Education," Washington, D.C.: American Society for Engineering Education, 1987. 
[27] National Science Board, The Role of the National Science Foundation in Economic Competitiveness, Washington, D.C.: National Science Board, 1988.

[28] MIT Commission on Industrial Productivity, "Education and Training for the United States: Development the Human Resources We Need for Technological Advance and Competitiveness," The Working Papers of the MIT Commission on Industrial Productivity, Cambridge, Massachusetts: MIT Press, 1989.

[29] Downey, G.L.,"CAD/CAM Saves the Nation?: Toward an Anthropology of Technology," Knowledge and Society Vol. 9, No. 143-168, 1992.

[30] Downey, G.L., The Machine in Me: An Anthropologist Sits among Computer Engineers, New York: Routledge, 1998.

[31] Lucena, J., Defending the Nation: U.S. Policymaking to Create Scientists and Engineers from Sputnik to the 'War Against Terrorism', Lanham, Maryland: University Press of America, Inc., 2005.

[32] Downey, G.L.," Low Cost, Mass Use: American Engineers and the Metrics of Progress," History and Technology Vol. 22, No. 3, 2007, pp. 289-308.

[33] Anderl, R., K. Gong, N. Cai Li, P. Kaminski, M. Netto, F. Kimura, J.R. Lohmann, B. Plattner, and B. Widdig, In Search of Global Engineering Excellence: Educating the Next Generation of Engineers for the Global Workplace, Hanover, Germany: Continental AG, 2006.

[34] The President's Council of Advisors on Science and Technology, "Sustaining the Nation's Innovation Ecosystems: Report on Information Technology, Manufacturing, and Competitiveness," Washington, D.C., 2004.

[35] Friedman, T.L., The World is Flat: A Brief History of the Twenty-First Century, New York: Farrar, Straus and Giroux, 2005.

[36] Committee on Prospering in the Global Economy of the 21st Century: An Agenda for American Science and Technology, Committee on Science, Engineering, and Public Policy, National Academy of Sciences, National Academy of Engineering, and Institute of Medicine of the National Academies, Rising Above the Gathering Storm: Energizing and Employing America for a Brighter Economic Future, Washington, D.C.: The National Academies Press, 2007, pp. 23-24.

[37] National Academy of Engineering, Educating the Engineer of 2020: Adapting Engineering Education to the New Century, Washington, D.C.: The National Academies Press, 2005, pp. 4, 10, 10.

[38] Sommerville, P.," Homelessness and the Meaning of Home: Rooflessness or Rootedness?," International Journal of Urban and Regional Research Vol. 16, 1992, pp. 528-539.

[39] Bell, D.," Insignificant Others: Lesbian and Gay Geographies," Area Vol. 23, 1991, pp. 323-329.

[40] Silverstone, R., E. Hirsch, and D. Morley, "Information and Communication Technologies and the Moral Economy of the Household," Consuming Technologies: Media and Information in Domestic Spaces, London: Routledge, 1992, pp. 15-31. 
[41] Valentine, G.," 'Sticks and Stones May Break My Bones': A Personal Geography of Harassment," Antipode Vol. 30, No. 4, 1998, pp. 305-332.

[42] Law, J., After Method: Mess in Social Science Research, London ; New York: Routledge, 2004.

[43] Abell, P.," Narrative Explanation: An Alternative to Variable-Centered Explanation?," Annual Review of Sociology Vol. 30, 2004, pp. 287-310.

[44] Atkinson, P., The Ethnographic Imagination: Textual Constructions of Reality, London: Routledge, 1990.

[45] Bruner, E.M., "Ethnography as Narrative," Memory, Identity, Community: The Idea of Narrative in the Human Sciences, Albany: SUNY Press, 1997, pp. 264-280.

[46] Bruner, E.M., Culture on Tour: Ethnographies of Travel, Chicago: The University of Chicago Press, 2005.

[47] Patterson, M., and K.R. Monroe," Narrative in Political Science," Annual Review of Political Science Vol. 1, 1998, pp. 315-331.

[48] Okely, J., "Anthropology and Autobiography: Participatory Experience and Embodied Knowledge, Pp. 1-29 in Anthropology and Autobiography, Judith Okely and Helen Calllaway, eds. London and New York: Routledge (Taylor \& Francis Group), 1992, pp. 2, 2.

[49] Adams, R., C. Allendoerfer, T.R. Smith, D. Socha, D. Williams, and K. Yasuhara, "Storytelling in Engineering Education," American Society for Engineering Education 2007 Annual Conference and Exposition: American Society for Engineering Education, 2007.

[50] Downey, G.L.," What is Engineering Studies For?: Dominant Practices and Scalable Scholarship," Engineering Studies: Journal of the International Network for Engineering Studies Vol. 1, No. 1, 2009, pp. 55-76.

[51] Baillie, C., Engineers within a Local and Global Society, San Rafael, California: Morgan \& Claypool Publishers, 2006.

[52] Catalano, G., Engineering Ethics, Peace, Justice, and the Earth, San Rafael, California: Morgan \& Claypool Publishers, 2006.

[53] Riley, D., Engineering and Social Justice, San Rafael, California: Morgan \& Claypool Publishers, 2008.

[54] Lucena, J., J. Schneider, and J.A. Leydens, Engineering and Sustainable Community Development, San Rafael, California: Morgan \& Claypool Publishers, 2010.

[55] Nieusma, D., and D. Riley," Designs on Development: Engineering, Globalization, and Social Justice," Engineering Studies Vol. 2, No. 1, 2010, pp. 29-59.

[56] Downey, G.L., and J.C. Lucena, "Engineers and Development: The Need for Engineering Studies," Engineering: Issues and Challenges for Development, Paris, France: UNESCO Publishing, 2010 [forthcoming].

[57] Dolby, N.," Encountering an American Self: Study Abroad and National Identity," Comparative Education Review Vol. 48, No. 2, 2004, pp. 150-173. 